\title{
RESENHA DO LIVRO ÓCIO VALIOSO PARA ENVELHECER BEM
}

\author{
Recebido em: 19/05/2019 \\ Aceito em: 18/11/2019
}

\author{
Hani Zehdi Amine Awad ${ }^{1}$ \\ Giuliano Gomes de Assis Pimentel ${ }^{2}$ \\ Universidade Estadual de Maringá (UEM) \\ Maringá - PR - Brasil
}

\begin{abstract}
RESUMO: Resenhamos o livro Ócio valioso para envelhecer bem, de Manuel Cuenca Cabeza, buscando elucidar o significado do ócio valioso e ativo enquanto prática de lazer na fase do envelhecimento. Para Cuenca a transição da atividade produtiva para a aposentadoria provoca mudança existencial, limitando a autoexpressão do idoso. Para viver com maior autonomia e sensibilidade a fase do envelhecimento, propõe ao aposentado experienciar um ócio ativo e dinâmico que lhe permita ter prazer e motivação para desfrutar a cada dia de sua existência. Mas, como seria possível o idoso viver esse ócio valioso, especialmente no contexto brasileiro?
\end{abstract}

PALAVRAS-CHAVE: Envelhecimento. Atividades de Lazer. Qualidade de Vida.

\begin{abstract}
A REVIEW OF THE BOOK VALUABLE LEISURE FOR AGING WELL
ABSTRACT: This paper presents a review of Manuel Cuenca Cabeza's Valuable Leisure for Aging Well, aiming to elucidate the meaning of valuable and active leisure as a leisure practice in the aging phase. For Cuenca, the transition from productive activity to retirement causes existential change, limiting the self-expression of the elderly. To live with greater autonomy and sensitivity the aging phase, it proposes that the retired persons experience an active and dynamic leisure that allows them to have pleasure and motivation to enjoy each day of their existence. However, how may it be possible for the elderly to live this valuable leisure, especially in the Brazilian context?
\end{abstract}

KEYWORDS: Aging. Leisure Activities. Quality of Life.

As recentes discussões sobre idade mínima para aposentadoria no Brasil nos desafiam a questionar se é possível um "ócio com dignidade", termo cunhado por

\footnotetext{
${ }^{1}$ Doutorando em Educação Física na Universidade Estadual de Maringá (UEM). Mestre em Educação (UFU). Docente do curso de Educação Física do Centro Universitário FAG. Membro do ${ }^{2}$ Doutor em Educação Física (UNICAMP). Docente do curso de Educação Física da Universidade Estadual de Maringá (UEM). Líder do Grupo de Estudos do Lazer (GEL/UEM).
} 
Sêneca (2018) para se referir a uma velhice sábia, ativa e criativa. É neste contexto fortuitamente são publicadas as reflexões acumuladas por Manuel Cuenca Cabeza sobre o valor do Ócio para o envelhecimento.

O autor nasceu em 1946 em Lucena (Córdoba - Espanha). É Catedrático Emérito de Pedagogia da Universidade de Deusto, em Bilbão. Iniciou os Estudos do lazer na universidade espanhola ao fundar, em 1988, o Instituto de Estudos de Ócio de Deusto, do qual foi diretor até setembro de 2011. Públicou 32 livros e numerosos capítulos de livros e artigos de pesquisa sobre assuntos relativos ao ócio e o lazer. Participou de vários congressos e reuniões científicas na Europa e na América, na qualidade de pesquisador e conferencista, sendo também promotor das redes de pesquisa Otium (presente em países ibero-americanos) e OcioGune (Espanha), centradas no estudo do ócio como desenvolvimento humano. Dirige a Coleção de documentos de estudos do ócio, publicada pela Universidade de Deusto desde 1995 e faz parte do Comitê Científico de 15 revistas científicas.

A obra com título original Ocio valioso para un envejecimiento activo $y$ satisfactorio foi vertida para a língua portuguesa por Francisco José M. Couto. O lançamento ocorreu durante o $15^{\circ}$ Congresso Mundial de Lazer, em São Paulo.

Em perspectiva interdisciplinar e orientada para o desenvolvimento humano, o livro é uma reunião de análises de Cuenca sobre as relações da população de idosos da Espanha com a busca da qualidade de vida, podendo aproximar, em partes, da realidade brasileira. No vocabulário espanhol a palavra ocio acolhe o sentido de lazer. Diferentemente, na sociedade capitalista brasileira o ócio possui sentido pejorativo, beirando a palavra ociosidade, significando o nada fazer, a abstenção total ao trabalho, causando um estado de desocupação, preguiça, vagabundagem. Com o envelhecimento 
da população mundial, a obra representa um convite para investigadores de diferentes áreas, dentre elas a Educação Física, que dedicam pesquisas ao idoso e a sua relação com o ócio, tempo livre, lazer, recreação, atividade física, saúde, cultura e práticas sociais.

Apresentada em linguagem positivista, a obra fornece um prólogo, seguido de 20 capítulos acompanhados de questões para debater e, epílogo final. Escrevendo na primeira pessoa, ao longo do livro, dialoga com mais de uma centena de autores de diferentes matrizes teóricas e tempos. O autor vai falar sobre o Ócio valioso no bom envelheceimento para refletir sobre a influência que o lazer pode exercer para a promoção de envelhecimento dinâmico e embasado nas experiências. Cuenca entende o ócio valioso como aquele capaz de dar significado a nossas ocupações cotidianas, por intermédio de aporte positivo que as atividades de lazer nos causam. Ao longo do livro alguns capítulos apresentam conteúdos que se aproximam; em vista disso, estão agrupados no decorrer da resenha.

O primeiro e segundo capítulo propõe combater os preconceitos e estereótipos negativos vinculados a velhice e, ao ócio. Reconhecendo que, na atualidade as pessoas ao chegarem a esta etapa da vida jamais foram tão bem informadas para a busca do bem-estar. Para tanto, indica ao idoso, abandonar estereótipos, cuidar da saúde física e mental, e saber desfrutar com sabedoria e experiência do novo período da vida com programas que se adpatem ao seu desejo e possibilidade.

O terceiro e o sexto capítulo possuem proximidade, abordando o "ócio e seus benefícios”. Esclarece que não se deve confundir ócio com tempo livre, pois, pode-se ter muito tempo disponível e jamais ter ócio. Subscreve vários temas como: “ócio e atividade", afirmando que qualquer atividade, das muitas que temos na vida, pode 
chegar ou não a ser ócio, em função da relação de desfrute e satisfação que estabelecemos com ela; "ócio e consumo", clarificando que tão importante quanto comprar produtos, é entender a sua necessidade e fruir para satisfação; "ócio valioso" sendo a afirmação de um ócio com valores benéficos para as pessoas e as comunidades, fundamentadas no reconhecimento da importância das experiências satisfatórias e de seu potencial pessoal e social; "os diferentes graus de desfrute" refere-se à satisfação e ao mesmo tempo a capacidade crítica que se consegue adquirir com o passar do tempo.

O quarto capítulo aborda o envelhecimento ativo, vinculado a preocupação com a saúde diante do envelhecimento crescente. O autor reconhece a importância do exercício físico, contudo, alega não ser suficiente, tendo que ser integrado ao bem-estar mental, conectividade social, o voluntariado e a aprendizagem ao longo da vida. $\mathrm{O}$ envelhecimento ativo propõe uma visão positiva e holística que pretende ser uma aspiração de cada pessoa e, ao mesmo tempo uma intenção política das sociedades que podem apresentar resultados significativos para um ócio valioso. Assim, propõe manter, prevenir e preservar uma saúde da maior qualidade possível.

No quinto capítulo propõe um envelhecimento satisfatório, colocando o ócio como importante possibilidade para o envelhecimento qualitativo. A aposentadoria conduz para três novas configurações: tempo livre; liberdade; diferentes formatos de vida. O autor pautado em estudos afirma que $90 \%$ da população espanhola considera que o lazer é importante ou muito importante em suas vidas. O termo "satisfatório" refere-se ao bem-estar que experimentamos quando fazemos algo com sentido e significado. O envelhecimento satisfatório acontece com a experiência do ócio, não para preencher o tempo, mas a realização, a superação e o desenvolvimento de cada um como pessoa, pois desperta seu interesse e o convida a descobrir novas situações. 
O sexto capítulo apresenta os benefícios do ócio como proativo para o favorecimento de novas descobertas e possibilidades. A prática de atividades de lazer pode trazer diferentes possibilidades de benefícios simultaneamente, ainda que se apresentem de distintas formas para cada pessoa. Muitas das vastas experiências do lazer têm afinidade com o movimento e a atividade física escolhida, o que ajuíza na manutenção da saúde e da forma física, evitando riscos de debilidade e prevenindo doenças crônicas e mentais. Os benefícios psicológicos podem ser de diferentes tipos, os mais sucessivos os emocionais, os cognitivos e os comportamentais que de modo geral cooperam para o bom humor e para satisfação pessoal. Os benefícios sociais surgem da influência que as experiências de ócio têm na comunicação interpessoal e nas aptidões sociais para estreitar os laços humanos. As experiências de ócio podem atuar como prevenção e manutenção de prevenções terapêuticas. $O$ ócio atua como experiência "paliativa" quando permite às pessoas se recomporem de acontecimentos relevantes na vida, como a perda de uma pessoa querida ou do emprego promovendo certo controle sobre as experiências estressantes. Alega que mudar as pessoas de uma situação passiva para ativa, não é tarefa fácil, garantindo que a animação sociocultural tem papel especial no desenvolvimento das pessoas e dos grupos, aos quais se devem facilitar processos de participação, comunicação e desenvolvimento social.

No sétimo capítulo o autor aborda a "plasticidade cognitiva e comportamental". Com os atuais avanços admitem reorientar a prática e redefinir a prioridade das competências do idoso. A plasticidade cognitiva é a capacidade que as pessoas apresentam de alterar o conhecimento cognitivo a partir da aprendizagem e transferir este conhecimento para outras tarefas semelhantes da vida. "A plasticidade neural e reserva cerebral" podem ser estimuladas positivamente com os idosos. A 
inflamação física, emocional ou social junto com a experiência acumulada e a educação recebida, é determinante para manter a reserva cognitiva e neuronal. Essa ideia fortalece que o ócio pode ser mais valioso que outro. Portanto, é possível manter a aprendizagem ao longo de toda a velhice, e que o desenvolvimento cognitivo é admissível com treinamento de algo que se aprecie verdadeiramente. Um ócio múltiplo que se vivencie por meio de práticas diversas e integrantes, mas que, ao mesmo tempo, tenha uma série de valores comuns, tais como motivação pessoal, vontade de superação e presença do conhecimento.

O oitavo capítulo trata do potencial dos passatempos para ampliar a sensibilidade do idoso. Os passatempos são oportunidades para quebrar a rotina, usar a criatividade e sentir o novo. Enquanto prática de lazer frequente tem maior probabilidade de apurar as habilidades individuais, ampliar as emoções positivas, tornando o idoso mais tolerante e predisposto para outros contextos da vida.

Os fatores que determinam o sucesso no processo de envelhecimento são tratados no nono e décimo capítulo, definindo três fatores predominantes: a percepção pessoal da condição de saúde; o círculo familiar e de amigos; e a educação como formação em seus diferentes níveis.

O décimo primeiro capítulo aponta contribuições do ócio para o desenvolvimento humano, alegando que ocorre a partir de duas capacidades básicas que se complementam: autonomia pessoal e conexão harmônica com o ambiente que vivemos. Desta forma, os métodos educativos em afinidade a atividades complexas como a leitura, o gosto pelas artes, o conhecimento da natureza ou as múltiplas manifestações esportivas somam neste processo de desenvolvimento pessoal do idoso. 
O lazer somente é satisfatório para uma pessoa quando é livre e habilmente selecionado na medida em que se assenta a seus interesses, circunstâncias e possibilidades.

Do décimo segundo ao vigésimo capítulo, apresentam-se as categorias do ócio e suas diversas correlações para um envelhecimento valioso. Inicia com o "ócio ativo", referindo-se as práticas na qual a pessoa se envolve com a participação física e mental numa relação psicossomática, sentindo-se protagonista na ação. “Ócio substancial”, em alusão as práticas de lazer que se reproduzem ao longo do tempo em busca de repetida satisfação, o que leva a pessoa a contrair habilidades, conhecimentos e experiências que favorecem a autossuperação e autoexpressão. "Ócio lúdico", para o autor é um modo de viver o jogo num contexto próprio como diversão nas diferentes fases da vida. Assinala que a experiência dos jogos proporciona diversão, emoção, alegria, satisfação, liberação, superação, risco e ressignificação da fantasia. “Ócio esportivo" é abordado pelo autor a partir da estreita relação do esporte com a satisfação pessoal que se obtém ao praticar esportes, jogos e outras modalidades arroladas com a atividade física. "Ócio criativo" baseia-se na ênfase da criação, transformando a existência em situações inéditas e intensas de serem vividas, proporcionando autorrealização e libertação da rotina. Apresenta-se sob duas diferentes vertentes, a "criação" e "recriação". O ócio criador tem caráter expressivo, com uma trajetória de dentro para fora. Admite expressar as experiências e ideias, manifestas na sensibilidade de cada um. A palavra "recriação" denota dar vida, recriar algo criado, vem de assimilar e reviver os métodos criativos, artísticos ou culturais. O "ócio recriativo" é receptivo, surge graças ao entendimento de uma mensagem de fora a que se obteve acesso a partir do conhecimento, abrindo possibilidade para o significado e sentido da ação pessoal e cultural. "Ócio cultural" é a possibilidade de "recriação" e a transmissão da cultura 
pelos quais se interessa com seus mais diversos significados, permitindo ao idoso acesso para uma gama de possibilidade e sentidos que se entrecruzam e são fontes de expressividade como a arte. "Ócio ambiental-ecológico" se evidencia pela vivência de experiências satisfatórias geradas de "estar" em um lugar e/ou ambiente. Concerne às experiências ao ar livre, a viajar e desfrutar da natureza, seja de um modo contemplativo ou da ação direta para com a natureza. "Ócio festivo" apresentado como manifestação social de lazer na qual se festeja determinado acontecimento conexo à vida, atendendo a uma necessidade não caracterizada na diversão instantânea. Para o autor, o ócio festivo está no extraordinário, sendo uma das ações de lazer das mais realizadas, ainda que nem sempre a que ofereça maior estado de prazer. $\mathrm{O}$ ócio festivo é vivido pelo idoso com um sentido marcado de celebração interior, tendo sentido quando compartilhado na companhia de familiares e no âmbito privado. "Ócio solidário" é uma experiência em que as vivências satisfatórias do idoso no lazer estão motivadas na atitude pessoal de ajudar a quem necessita e ao ambiente em que se vive independentemente do setor de intervenção.

Fica evidente a inquietação e o cuidado do autor em manter coerência em difundir o valor de uma orientação consciente do idoso para com o ócio/lazer valioso e ativo. Todavia, percebe-se que o livro, foi direcionado para leitores de diversas áreas atribuindo-se importância, da educação à saúde, do idoso ao pesquisador, portanto, no transcorrer a obra retoma várias de suas argumentações, apontamentos e análises.

Garantir, educar e promover ações que aproximem a comunidade idosa de “valioso" lazer é essencial e digno. Não há dúvidas do potencial social, biológico, psicológico e afetivo que o lazer pode promover junto ao idoso, ainda mais quando amparadas por profissionais de diversas áreas. 
Todavia, apesar dos significativos avanços sociais na saúde, urbanismo, tecnologia e disseminação de conhecimentos, a realidade do Brasil com população quase quatro vezes maior que da Espanha sinaliza ainda uma cultura internalizada no trabalho, no assistencialismo e até certo ponto no abandono das políticas ao idoso. Ao chegar à aposentadoria, muitos que deveriam gozar o pleno direito de desfrutar da sua "terceira idade" com qualidade e autonomia vivenciando o seu ócio/lazer, se vê na condição de voltar a ocupar um novo posto de trabalho com salários reduzidos para auxiliar o alto custo de subsistência pessoal ou de terceiros.

Concorda-se com Cuenca que o desfrute do envelhecimento começa com atitude de superação do conformismo e, com constante (re)educação para o acesso e a vivência ao lazer. Para que o lazer possa assumir papel essencial em nossa sociedade, faz-se necessário criar mecanismos dos mais diversos para que todos e especialmente o idoso nesta etapa da vida, possam se beneficiar com qualidade deste direito. E os profissionais de Educação Física, Pedagogia, Arte, Turismo, Sociologia, Assistência Social podem ser os interessados desta obra e a partir dela pensar na promoção de ações individuais e integradas aos órgãos governamentais para efetivação de politicas públicas voltadas para o direito do idoso na vivência de um lazer/ócio valioso, ativo, humano e extensivo a todos.

\section{REFERÊNCIAS}

CUENCA CABEZA, Manuel. Ócio valioso para envelhecer bem. São Paulo: Edições SESC, 2018.

SÊNECA, Lúcio Anneo. Aprendendo a viver: cartas a Lucílio. Porto Alegre: L\&M Pocket, 2018. 


\section{Endereço dos Autores:}

Hani Zehdi Amine Awad

Rua Jataí, 118 - Recanto Tropical

Cascavel - PR - 85.807-120

Endereço Eletrônico: hani@hani.com.br

Giuliano Gomes de Assis Pimentel

Universidade Estadual de Maringá (UEM)

Departamento de Educação Física

Av. Colombo, 5790 / Bloco M06 - Sala 15 - Campus Universitário

Maringá - PR - 87.020-900

Endereço Eletrônico: ggapimentel@uem.br 